\title{
3D-Printed Objects for Multipurpose Applications
}

Nayem Hossain, Mohammad Asaduzzaman Chowdhury, Md. Bengir Ahmed Shuvho, Mohammod Abul Kashem, and Mohamed Kchaou

Submitted: 4 November 2020 / Revised: 24 February 2021 / Accepted: 4 March 2021 / Published online: 26 March 2021

\begin{abstract}
3D printing is a popular nonconventional manufacturing technique used to print 3D objects by using conventional and nonconventional materials. The application and uses of $3 \mathrm{D}$ printing are rapidly increasing in each dimension of the engineering and medical sectors. This article overviews the multipurpose applications of 3D printing based on current research. In the beginning, various popular methods including fused deposition method, stereolithography 3D printing method, powder bed fusion method, digital light processing method, and metal transfer dynamic method used in 3D printing are discussed. Popular materials utilized randomly in printing techniques such as hydrogel, ABS, steel, silver, and epoxy are overviewed. Engineering applications under the current development of the printing technique which include electrode, 4D printing technique, twisting object, photosensitive polymer, and engines are focused. Printing of medical equipment including artificial tissues, scaffolds, bioprinted model, prostheses, surgical instruments, COVID-19, skull, and heart is of major focus. Characterization techniques of the printed 3D products are mentioned. In addition, potential challenges and future prospects are evaluated based on the current scenario. This review article will work as a masterpiece for the researchers interested to work in this field
\end{abstract}

Keywords characterization, challenges, 3D printed, medical applications, printing applications, simulation

\section{Introduction}

$3 \mathrm{D}$ objects are created by the successive layers of material controlled digitally by three-dimensional printing. Complex parts which are time-consuming and expensive by traditional methods can be produced in less time and at low cost by 3D printers. Both prototype and functional parts are produced rapidly and accurately without making any waste. It is also considered sometimes as a new industrial revolution (Ref 1).

This invited article is part of a special topical focus in the Journal of Materials Engineering and Performance on Additive Manufacturing. The issue was organized by Dr. William Frazier, Pilgrim Consulting, LLC; Mr. Rick Russell, NASA; Dr. Yan Lu, NIST; Dr. Brandon D. Ribic, America Makes; and Caroline Vail, NSWC Carderock.

Nayem Hossain, Department of Mechanical Engineering, International University of Business Agriculture and Technology (IUBAT), Dhaka 1230, Bangladesh; and Department of Mechanical Engineering, Dhaka University of Engineering \& Technology (DUET), DUET, Gazipur 1707, Bangladesh; Mohammad Asaduzzaman Chowdhury, Department of Mechanical Engineering, Dhaka University of Engineering \& Technology (DUET), DUET, Gazipur 1707, Bangladesh; Md. Bengir Ahmed Shuvho, Department of Industrial and Production Engineering, National Institute of Textile Engineering and Research (NITER), Savar, Dhaka 1350, Bangladesh; Mohammod Abul Kashem, Department of Computer Science and Engineering, Dhaka University of Engineering \& Technology (DUET), DUET, Gazipur 1707, Bangladesh; and Mohamed Kchaou, Department of Mechanical Engineering, College of Engineering, University of Bisha, Bisha 67714, Kingdom of Saudi Arabia; and Laboratory of Electromechanical Systems (LASEM), National Engineering School of Sfax, University of Sfax, 3038 Sfax, Tunisia. Contact e-mails: asadzmn2014@yahoo.com and asad@duet.ac.bd.

For the ease of consolidation, early additive manufacturing applications emphasized on the use of polymers either through a photopolymerization or thermal process (Ref 2,3). Because of technological transmission, there has been an increased uptake of metal-based additive manufacturing used as a prototyping tool to make end products (Ref 4$)$. The main technologies for 3D printing are direct metal laser sintering, electron beam melting, FDM using a metal-filled polymer filament, and directed energy deposition (Ref 5-8).

Various materials and techniques are utilized in the 3D printing process. The top-down lithography process is one of them that includes two-photon polymerization, focused ion beam, and electron beam -lithography, and therefore, it can produce precise patterning with the desired shape using a layerby-layer profile (Ref 9-11). Fused deposition of polymer is another type of popularly used 3D printing process where machines are not expensive and easy to operate (Ref 12). Both conventional polymers and polymer composites containing solid particles can be used to print. Among the commonly used materials, hydrogel materials are commonly used for their capacity as bioinks in a 3D printing system for cell printability and encapsulation (Ref 13). Composite materials are employed in $3 \mathrm{D}$ printing for the fabrication of complex geometries because of having superior thermal, mechanical, and electrical properties (Ref 14-16). Besides, having the ability to respond to external stimuli like water, temperature, and light smart materials has significant applications in 3D printing (Ref 1720).

Applications of 3D printing in medical, industrial, automotive, construction, architecture, electronics, aerospace, and decorative sectors are abundant. Complex composite tissue constructs are created by 3D printing in a layer-by-layer fashion where cell-laden hydrogels are precisely placed (Ref $21,22)$. Battery components including a separator, electrodes, current collector, and solid polymer electrolyte are customized within the final optimized design 3D object through the direct incorporation of microbatteries and electronics (Ref 23-27). Within a short time, complex-shaped microstructures 
and geometries can be built (Ref 28, 29). By using microelectromechanical systems microstructured metals are being manufactured from ceramics (Ref 30, 31). Conductive fillers made conductive nanocomposites manufactured by $3 \mathrm{D}$ printing have potential applications in the fields of robotics, tactile sensors, and microelectromechanical systems (Ref 3235).

Application of additive manufacturing particularly in medical science and medicine shows tremendous improvement (Ref 36). Current research on additive manufacturing for medical applications is focused on four main areas, and the areas are: (1) pathological organ models manufacturing research to aid surgical treatment analysis and preoperative planning (Ref 37); (2) personalized manufacturing research to make permanent nonbioactive implants; (3) local bioactive and biodegradable scaffolds fabrication research; (4) organs and tissues printing research for complete life function (Ref 38-40). To manufacture medical equipment, additive manufacturing makes the best use of raw material with minimum waste, make better mechanical integrity and the geometrical accuracy become satisfactory. The metals used in medical applications are typically titanium, titanium oxide, stainless steel, titanium nitride, zirconium oxide, carbon nitride, and cobalt chromium alloys (Ref 41, 42).

\section{Mechanisms of 3D Systems}

\subsection{Methods}

Manufacturing of 3D products by 3D printers is performed by various methods. The fused deposition is considered one of the most popular and economical methods where thermoplastic polymers are used for the preparation of filament suitable for a 3D printer (Ref 43). In this method, cheap complicated items can be produced with reduced waste (Ref 44). Thin layers of melted thermoplastic material are deposited in this process in many successive passes for making the desired 3D object where the computer controls a heated nozzle in the direction of the $\mathrm{XYZ}$-axis. After extrusion, the thermoplastic material instantaneously cools down to be deposited and the material is heated only a few degrees above its melting temperature. Transparent parts with photo-induced layer can be produced allowing UV absorbers having the thickness typically around 50-200 $\mu \mathrm{m}$ (Ref 45).

Due to the advantages of low cost, short cycle time, and high precision to manufacture complex-shaped ceramic parts stereolithography 3D printing is widely employed. Stereolithography $3 \mathrm{D}$ printing has produced $\mathrm{SiO}_{2}, \mathrm{Al}_{2} \mathrm{O}_{3}, \mathrm{ZrO}_{2}$, bioceramics, and lots more. In order to make optical mirrors in recent years, 3D printing has been applied for the manufacturing functions of ceramics and ceramics matrix composites. The stereolithography $3 \mathrm{D}$ printing process is rarely observed in the studies to make SiC ceramic and its optical components (Ref 46).

The laser beam is a subset of powder bed fusion where solid objects are created by heating solid particles. In the process, they are also fused together at their surfaces. Carl Deckard developed the technology based on a neodymium-doped yttrium aluminum garnet in 1984. The printer made many prototypes by acrylonitrile butadiene styrene (ABS) and thermoplastic polymer (Ref 47).
Digital light processing is another popular 3D printing method where complex-shaped ceramic parts are fabricated. Personalized structured $\mathrm{ZrO}_{2}$ ceramic teeth having a good mechanical property, biocompatibility, and strong potentiality in the field of oral restoration are prepared by this method. This method also produced fine lattice structural titanium dioxide ceramic and porous $\mathrm{BN}-\mathrm{SiO}_{2}$ ceramics (Ref 48).

Metal transfer dynamics are investigated in depth in the wire feeding-based electron beam $3 \mathrm{D}$ printing process. Here the experiments are combined with novel modeling of the heat transfer and molten flow behaviors. Experimental and simulation results recognize different metal transfer modes and are revealed quantitatively. A simple theory determines the relationship between the mode good for forming quality and the process parameters (Ref 49).

\subsection{Materials}

Many different materials can be used in 3D printing to manufacture products. In medical science hydrogel materials for example collagen, gelatin, and alginate are commonly used as bioinks. Collagen hydrogel is the most abundant natural polymer found in mammalian tissue. It has the capability of providing a favorable microenvironment because of having a native extracellular matrix, and for this, it is commonly utilized for the regeneration of vasculature, bone, liver, and nerves (Ref $50)$.

ABS (acrylonitrile butadiene styrene) is used in 3D printing for mechanical and electrical works. Sezer et al. (Ref 51) utilized ABS matrix MWCNTs filler nanocomposites in their research of additive manufacturing. In the process ABS with MWCNTs was compounded with a twin-screw microextruder keeping the screw speed at $100 \mathrm{rpm}$ in the dispersion process. To avoid degradation of the ABS $240{ }^{\circ} \mathrm{C}$ temperature was kept constant in the extruder for 5 minutes to ensure complete melting and mixing. Maintaining the weight percentage 1, 3, 5, 7 , and 10, the MWCNT/ABS nanocomposite samples were prepared.

In order to satisfy the mechanical properties steel is reinforced with other materials to give higher strength. $\mathrm{Li}$ et al. (Ref 52) reinforced steel microcable with a geopolymer composite in his $3 \mathrm{D}$ printing research for the mechanical improvement of the product. $1.2 \mathrm{~mm}$ of diameter continuous steel microcable having 7 shares and each share had 19 strands was extruded from the print head along with the geopolymer. Steel microcable small curvature was ensured by using a 15mm-diameter round nozzle during printing. After attempting several times, the horizontal printing speed and the steel microcable entering speed are kept equal.

Silver is extensively used in $3 \mathrm{D}$ printing to print dental materials. Liao et al. (Ref 53) utilized silver nanoparticles with zirconium oxide to strengthen dental base composites in $3 \mathrm{D}$ printing. In the process they utilized, desired materials were synthesized at two different stages. In the first stage, nanosilverloaded zirconium phosphate was salinized under an acidic condition with MPS. 4.0 g 6S-NP3 and $150.0 \mathrm{~g}$ deionized water were mixed in a clean beaker for ultrasonic dispersion for $1 \mathrm{~h}$. Meanwhile, with constant speed injection, $1.0 \mathrm{~g}$ acetic acid, and $50.0 \mathrm{~g}$ deionized water were dropped together. The suspension was charged with a machine stirring $(200 \mathrm{r} / \mathrm{min})$ into a $500-\mathrm{mL}$ four-neck flask and heated to $30{ }^{\circ} \mathrm{C}$ followed by adding into the system in $1 \mathrm{~h}$ with the mixture of MPS and cyclohexane. The mixture temperature reached $80{ }^{\circ} \mathrm{C}$ and maintained the reaction 
for $1.5 \mathrm{~h}$. Using acetone M-6S-NP3 (methyl nanosilver-loaded zirconium phosphate) was created through extraction, and then, the solution was dried in the vacuum oven for $12 \mathrm{~h}$ at $80{ }^{\circ} \mathrm{C}$. At the next stage, M-6S-NP3 was grafted with PMMA where free radical polymerization was used. $1.0 \mathrm{~g}$ M-6S-NP3 was dispersed in a $250-\mathrm{mL}$ four-neck flask in $50.0 \mathrm{~g}$ xylene with the help of a stirring machine and then dispersed ultrasonically for $0.5 \mathrm{~h}$. Then, under nitrogen atmosphere, $10.0 \mathrm{~g}$ MMA and $0.1 \mathrm{~g}$ BPO initiator were added. In a water bath, the mixed suspension was kept stirring at $80{ }^{\circ} \mathrm{C}$. The P-6S-NP3 was obtained after 8.0 -h polymerization through centrifugal separation and extraction with acetone and then dried for $12 \mathrm{~h}$ at $80{ }^{\circ} \mathrm{C}$ in a vacuum oven.

Epoxy materials give desirable properties with improved mechanical, thermal, and chemical properties to the 3D-printed materials. For extrusion-based 3D printing, nanoclays can be used in epoxy or short fiber composite inks for the purpose of direct-write (DW) additive manufacturing (AM) so that it can be imparted in nearly ideal rheological properties. In general, significant effort is given so that polymer matrix composited can be used in $3 \mathrm{D}$ printing, and rapid progress is observed in epoxy-based composite materials. Hmeidat et al. (Ref 54) et al. used epoxy nanocomposites for making high-strength 3Dprinted materials. With appropriate amounts of nanoclay or fumed silica, the process inks were prepared by mixing the epoxy resin in $185-\mathrm{mL}$ plastic containers using a centrifugal planetary Speed Mixer. Using $30 \mathrm{~g}$ of Epon 826 resin and $1.5 \mathrm{~g}$ of the curing agent (VS03) six formulations, plus the control, were prepared. Under vacuum at $0.1 \mathrm{~atm}$ for $60 \mathrm{~s}$, the contents were mixed at $1700 \mathrm{rpm}$. After 60 seconds of mixing at 1700 rpm and $0.1 \mathrm{~atm}$, the nanofiller was added. Then, they scraped the container with a spatula so that the nanoclay can be kept the mixture completely dispersed and bubble-free by mixing for an additional $60 \mathrm{~s}$ at $1800 \mathrm{rpm}$ and $0.1 \mathrm{~atm}$.

\section{Multi-Applications of 3D Systems}

\subsection{Printing Applications}

Numerous applications are visible of 3D printing in printing applications. The 3D-printed electrode is one of them which can be printed both vertically and horizontally. The incorporation of smart materials or programmable materials that have the stimuli in temperature, water and light in 3D printing has brought a new dimension called 4D printing (Ref 55). Sun et al. (Ref 56) fabricated 4D material by a continuous printing technique. Localized thermal recovery is achieved after different loadings of polyplasticized material mentioned in Fig. 1. During the fabrication process, PLA pellets were first dried for $24 \mathrm{~h}$ at $80{ }^{\circ} \mathrm{C}$. $10 \mathrm{wt} . \%$ and 30 wt.\% were used then as a plasticizer by melt-blending to PLA using a microcompounder for $10 \mathrm{~min}$ at $170{ }^{\circ} \mathrm{C}$ and $100 \mathrm{RPM}$. They fabricated the 3Dprintable PLA/PEG filaments by attaching an automatic roller, after compounding at the end of the compounder. The 4D components were fabricated by a customized 3D FDM printer using a standard $0.3-\mathrm{mm}$ nozzle keeping the nozzle temperature of $180{ }^{\circ} \mathrm{C}$. Reshapable arc-shaped components were printed later by compression force into a flat configuration.

Products with rotational and twisting capabilities are manufactured with the help of 3D printing. Tuning elements having to twist and rotational bistable structures have been fabricated by Jeong et al. (Ref 57). In the fabrication procedure, they used the polyjet process in a Stratasys multi-material 3D printer where ultraviolet light was used for jetting the photopolymer ink droplets. They also created fine features with about $50 \mu \mathrm{m}$ resolution in the plane and $15 \mu \mathrm{m}$ in thickness by the process. Before importing into the Stratasys printer geometric design was first created using CAD software. Without postassembly and using a consolidated design they fabricated twisting and rotational bistable components. They used some special joints that allowed 3D printing of the whole components such as twisting components used ball joints, rotational used pin joints.

$3 \mathrm{D}$ printing has the advantages of producing polymeric material over other methods. Transparent, light and photosensitive polymer material has been fabricated by Wang et al. (Ref 58). A rigid, nearly colorless material exhibiting dimensional stability with the trade name VeroClearRGD 810 resinous material has been chosen for the experiment. By using AutoCAD cylindrical and dog-bone-shaped specimens were created at first. The specimen was printed by the Object Studio program then.

Engines for optical communication are fabricated by $3 \mathrm{D}$ printers. Hybrid multi-chip assembly of optical communications engines has been fabricated by Bleicher et al. (Ref 59) by in situ 3D nanolithography. In the process, they fabricated all PWB structures where a modified commercial two-photon lithography system was utilized. An fs laser having a pulse length of $100 \mathrm{fs}$ along with a repetition rate of $80 \mathrm{MHz}$ has been used as a lithography light source. The proprietary control software was used for allowing the precise localization of coupling interfaces and automated the PWB fabrication with high shape fidelity used to equip the lithography system.

\subsection{Medical Applications}

The invention of 3D printing has brought a new era for medical science. Numerous materials are being printed for the applications in this field. In the field of tissue engineering, artificial tissues are being developed by controlled deposition and cells (Ref 60). Kang et al. (Ref 57) synthesized bioprinted tissue by depositing cell-laden hydrogels together with a synthetic biodegradable polymer. That was accomplished in the following ways: they designed multi-dispensing modules for delivering different cell types and polymers in a single construct, they made a carrier material to deliver cells in a liquid form to discrete locations in the $3 \mathrm{D}$ structure, they designed a sophisticated nozzle system where the resolution was $2 \mu \mathrm{m}$ for biomaterials and $50 \mu \mathrm{m}$ for cells, they linked together cell-laden hydrogels after passage through the nozzle system, they printed an outer sacrificial acellular hydrogel mold simultaneously and dissolved after acquiring enough rigidity by tissue construct to retain its shape, and they created a lattice of microchannels that could nutrient and diffuse oxygen into the printed tissue constructs.

Hybrid microscaffolds are being produced with the help of 3D printing. Tan et al. (Ref 61) applied a new biofabrication strategy called hybrid microscaffold-based 3D bioprinting of multicellular constructs that could produce products having compressive strength. High specific surface areas are provided by the highly porous microscaffolds to get the anchoragedependent cells capable of attaching infiltrate and grow before extrusion-based printing. That property will expand the cells seeded on the microspheres where it will be exploited in stirred 

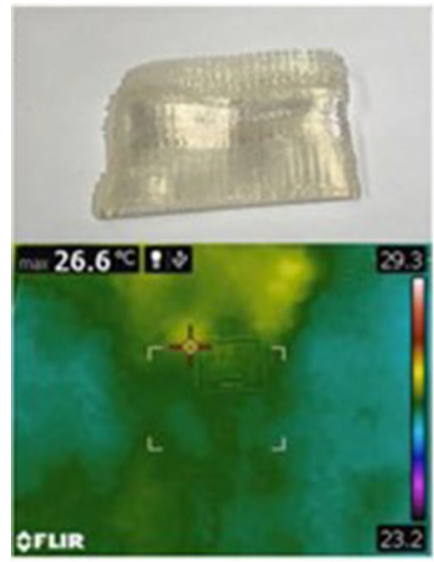

(a)
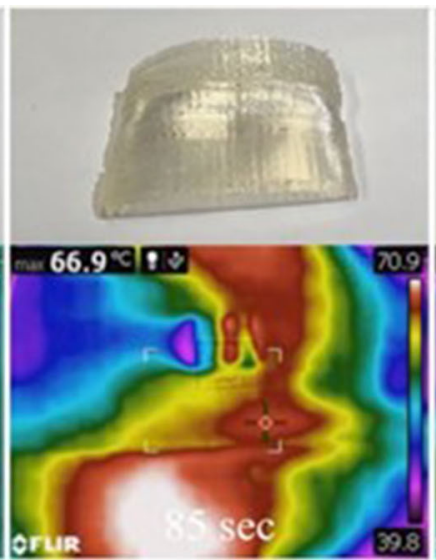

(b)
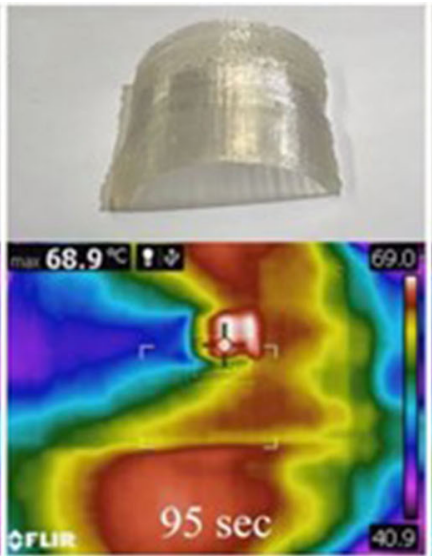

(c)

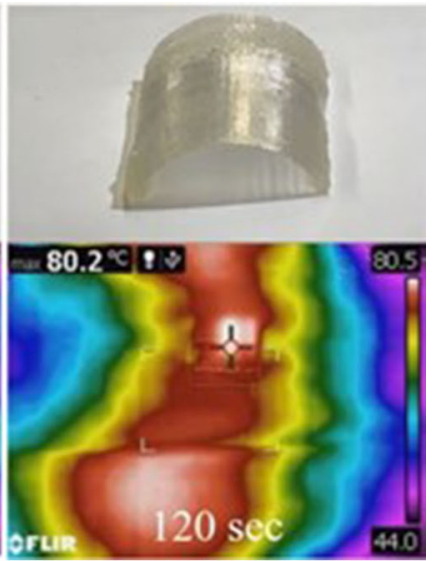

(d)

Fig. 1 Thermal recovery of 4D functionally graded model (Ref 56). Licensed under Creative Commons Attribution 4.0 International Public License, https://creativecommons.org/licenses/by/4.0/

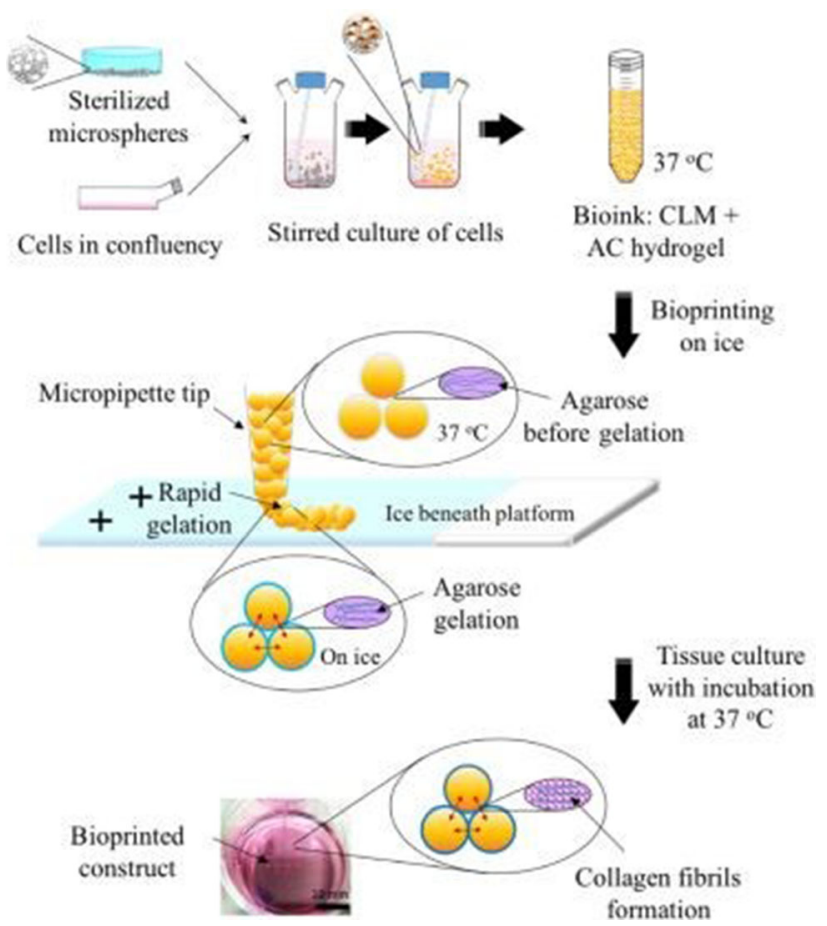

Fig. 2 Schematic illustration of the bioprinting process (Ref 58). Licensed under Creative Commons Attribution 4.0 International Public License, https://creativecommons.org/licenses/by/4.0/

or perfused culture and no passaging will take place from cellladen microspheres (CLMs). Together with thin hydrogel encapsulation, those CLMs could act as a bioink material for 3D bioprinting when the CLMs were lubricated by the printing hydrogel and glued after printing upon gelation shown in Fig. 2.

Bioprinted models are another product of 3D printing. 3D bioprinted model capable of evaluating the effect of stiffness on neuroblastoma cell cluster dynamics and behavior has been fabricated by Monferrer et al. (Ref 62). For the fabrication purpose, required cells were collected and expanded in a growth medium. Cells were cultured and trypsinized to create the bioinks. With the prepolymer solution, the resulting pellet was resuspended and loaded in a bioprinting syringe. Morley et al. (Ref 63) fabricated 3D bioprinted structural elements. In the fabrication process, an ionizable comonomer is prepared by cross-linking polyacrylamide microgels with 17 mol.\% methacrylic acid. Another solution was prepared in $490 \mathrm{~mL}$ ethanol by $8 \%(\mathrm{w} / \mathrm{w})$ acrylamide, $2 \%(\mathrm{w} / \mathrm{w})$ methacrylic acid, $1 \%(\mathrm{w} / \mathrm{w})$ poly(ethylene glycol) diacrylate $(\mathrm{MW}=700 \mathrm{~g}$ $\left.\mathrm{mol}^{-1}\right)$, and $0.1 \%(\mathrm{w} / \mathrm{w})$ azobisisobutyronitrile. The solution was placed into a preheated oil bath after sparging with nitrogen for $30 \mathrm{~min}$ at $60{ }^{\circ} \mathrm{C}$. The reaction mixture was heated after forming white precipitation for $4 \mathrm{~h}$. Then the microparticles were triturated after filtration with $500 \mathrm{~mL}$ of ethanol overnight. The solids were collected again and dried. The purified microgel powder was dispersed, mixed, and neutralized. For each type, the microgel 3D printing is prepared along with the culture medium. Using 12-well plates of single $35-\mathrm{mm}$ Petri dishes, fabrication of microbeams was enabled.

$3 \mathrm{D}$ printing also helps in a bone generation. Bioceramic scaffolds stimulate pediatric bone regeneration has been fabricated by Wang et al. (Ref 64) with the help of 3D printing. At the beginning of the process for the visualization of the rabbit's calvarium, a 13-mm skin incision was created. For exposing calvarial bone periosteum and soft tissue were dissected. Using $10 \mathrm{~mm}$ diameter trephine defects were created. Then the defects were repaired with either 3D-printed scaffolds loaded with $1000 \mu \mathrm{M}$ DIPY or bone graft where a fit-and-fill method was used. Proper inset was ensured when the violation of the dura mater was avoided, and the primary stability of the scaffold was obtained. Then calvarial bone graft was created by the immersion of trephined calvarium in saline solution. On the right aspect of the midface, a 13-mm skin was created in the alveolus. The soft tissue, alveolar ridge, and the maxillary suture and periosteum were dissected for the visualization of the maxilla. 3D-printed template was produced by either 3Dprinted scaffold loaded with $1000 \mu \mathrm{M}$, DIPY or bone graft defects were repaired again with the help of a fit-and-fill method so that reconstruction primary stability and avoiding violation of the maxillary sinus membrane were ensured. Before creating the maxillary defect, an alveolar bone graft was created by harvesting radial bone from the right rabbit forearm and 10-mm longitudinal incisions were made. 
Innovative approaches like incorporating antibiotics into $3 \mathrm{D}$-printed constructs are done by 3D printing. The common applications are medical implants, prostheses, and surgical instruments. Increased surface area for drug distribution, sequential layers of antibiotics and the ability to rapidly fabrication is permitted by 3D-printed antibiotic-impregnated devices. Table 1 shows the advantages and disadvantages of inkjet, fused deposition modeling, and stereolithography 3D printing techniques to incorporate antibiotics into 3D-printed constructs, and a short summary of recent bioprinting is shown in Table 2.

There has been a shortage of personal protective equipment (PPE) in many countries of the world due to the current COVID-19 pandemic where 3D printing is playing a good role. Breathing device is one of the most wanted devices for patience in many countries. As the normal production and the key pieces of PPEs cannot match the current demand, other means of manufacturing for these items are being practiced in many countries. Face masks, face shields, Venturi valves, and other oxygen masks are examples of 3D-printed products. Due to additive manufacturing certified medical devices have been delivered to the market in short possible times (Ref 76).

Based on the patient's situation additive manufacturing allows to print implants. More affordable and more precise alternative to bone cement have been developed by Dinesh et al. (Ref 77) for individualized implants. By the help of a CT scanning image, the team of Moiduddin et al. (Ref 78) created a $3 \mathrm{D}$ digital model of patient's skull and printed the model and implant where they used fused deposition modeling method. The printed implant had similar properties to the actual bone. Skull defects can be reconstructed by using a synthetic material known as hyperelastic bone by $3 \mathrm{D}$ printing method. This synthetic material contains bone mineral hydroxyapatite as well as common polyglycolic acid biocompatible material. For being lattice network, hyperelastic bone can be reconstructed allowing new bone material to grow (Ref 36).

In the field of cardiology, additive manufacturing is showing its excellence. For the communication of doctors with patients in some unique medical situations, patient's heart can be created by $3 \mathrm{D}$ printing. Additive manufacturing is relatively quick and cost-effective method to produce $3 \mathrm{D}$ anatomical heart models to develop surgical planning as well as treatment outcomes. Similar models can also be used in medical training program to train surgeon (Ref 79). For the development of vascular stents, additive manufacturing can also be applied to manage blood flow obstruction. On-demand and custom-fit can be created by this method for each patient. Thicker or thinner design can be created by customizing of stents around stressed or unstressed region of a vessel in order to increase blood flow (Ref 80). 3D printing is also useful in cardiology to design scaffolds. Melt extrusion technique is applied to produce this type of scaffolds that enable heart regeneration following a heart attack (Ref 81).

The production of orthopedic aids is now more accurate, more automated as well as less expensive due to the application of additive manufacturing in making these aids. A method has been described by Molnar and Morovi (Ref 82) where a custom-fit orthopedic corset has been produced for lower back support. In the method, a digital model was created by scanning the patient. CAD software has been used to prepare a custom-fit orthopedic corset using the data from the scan. Then, by applying the fused deposition method the corset was printed (Ref 83). Polylactic acid and polyethylene terephthalate glycol were used to make the corset because the materials needed to be both printable and biocompatible.

\section{Simulation and Characterization of 3D Struc- ture}

3D-printed materials are simulated and characterized by different techniques. Park et al. (Ref 75) performed an SEM test to characterize 3D-printed electronics made of conductive cellulose composites with a low porcelain threshold. Embedded conductive fillers which are in an insulative polymer matrix are shown in images. Figure 3(a) with a higher volume fraction is compared with Fig. 3(b) having a lower volume fraction. Clusters forming the localized percolation networks are seen in Fig. 3(b). This shows a well-matched resistivity change result in the simulation. In between Fig. 3(a) and (b), comparatively higher resistivity is observed in Fig. 3(a).

EDS spectrum analysis is used to show the chemical composition of the 3D-printed material. EDS analysis of the additive manufactured 3D nanoarchitect metals is performed by Andrey Vyatskikh et al. (Ref 84). The spectrum taken from a beam section shows the chemical composition as $91.8 \mathrm{wt} \% \mathrm{Ni}$, 5.0 wt. \% O, and 3.2 wt.\% C shown in Fig.4(a). TEM analysis is performed to show the presence of nanoparticles in the manufactured products. Hyunwoo Yuk et al. (Ref 85) performed the TEM analysis in 3D printing of conducting polymers. The image shows the dilute dispersion of nanofibrils in the solution shown in Fig. 4(b).

Different mechanical tests are also performed in the 3Dprinted structures. Bending with bare hand and simple radial

Table 1 Advantages and disadvantages of inkjet, fused deposition modeling, and stereolithography 3D printing techniques to incorporate antibiotics into 3D-printed constructs (Ref 65)

\begin{tabular}{llll}
\hline Process & \multicolumn{1}{c}{ Inkjet } & $\begin{array}{c}\text { Fused deposition } \\
\text { modeling }\end{array}$ & Stereolithography \\
\hline $\begin{array}{l}\text { Material choice } \\
\begin{array}{c}\text { Thermal degradation of added } \\
\text { antibiotic }\end{array}\end{array}$ & $\begin{array}{l}\text { Limited } \\
\text { Only if postprocessing involves heating }\end{array}$ & $\begin{array}{l}\text { Wide variety } \\
\text { Possible }\end{array}$ & $\begin{array}{l}\text { Limited } \\
\text { Not applicable }\end{array}$ \\
$\begin{array}{l}\text { Ultraviolet degradation of added } \\
\text { antibiotic }\end{array}$ & Not applicable & Not applicable & Possible if drugs used are ultraviolet sensitive \\
$\begin{array}{c}\text { Mechanical reduction with add- } \\
\text { ing antibiotic }\end{array}$ & None in one study & Possible & Unknown \\
\hline
\end{tabular}




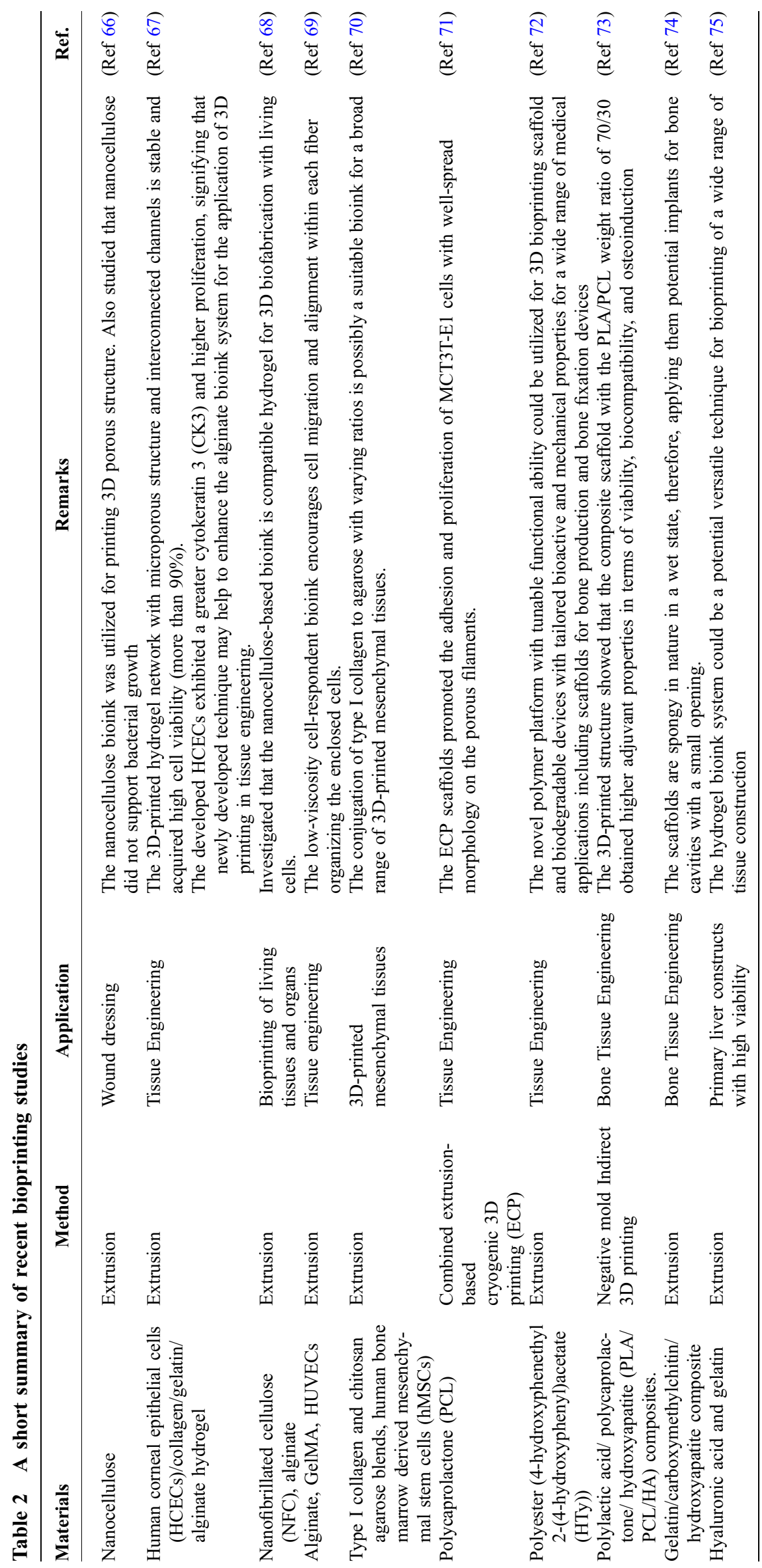




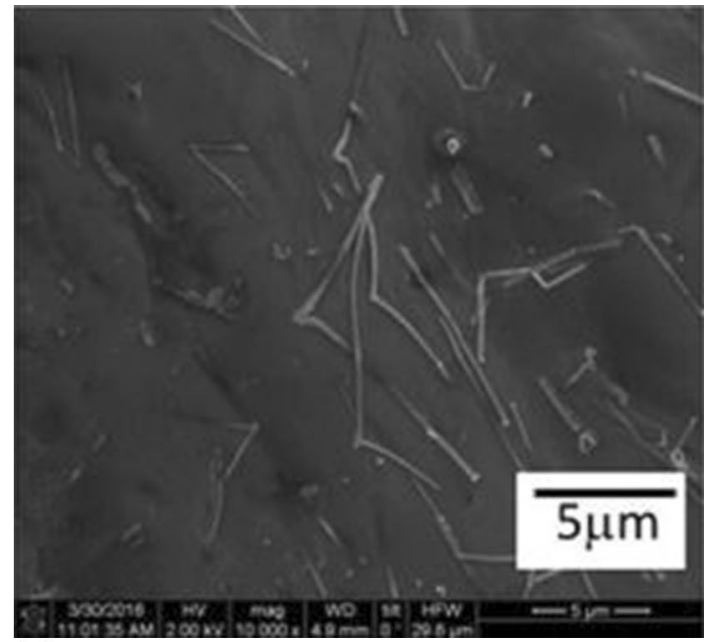

(a)

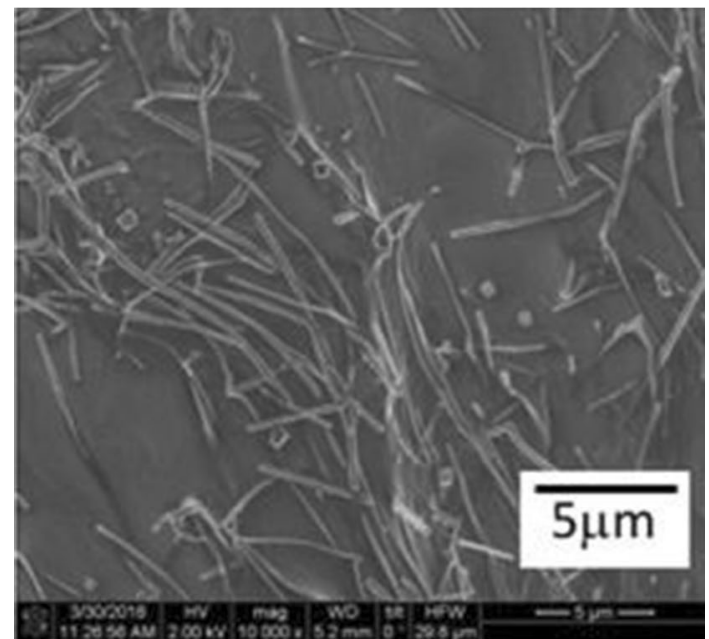

(b)

Fig. 3 Computational design and percolation evaluation of 3D conductor and experimental percolation threshold of 3D conductor (a) SEM image of 0.3 Vol. \% AgNW in CMC, (b) SEM image of 1.9 Vol. \% AgNW in CMC (Ref 75). Licensed under Creative Commons Attribution 4.0 International Public License, https://creati vecommons.org/licenses/by/4.0/

direction compression are among them. The shape was recovered after applying compression and bending force to the original state for the 3D-printed 2L-P MFT construct without breaking down as seen in Fig. 5(e). For each case of the MFT constructs the ultimate strength was calculated based on the stress-strain curves, and the results were $2.16 \pm 0.6,8.60 \pm$ $0.7,7.15 \pm 1.3$, and $13.50 \pm 1.3$, respectively (Fig. 5(f, g). The calculated Young's modulus was found for each case as 25.32 $\pm 10.02,66.43 \pm 2.97,66.94 \pm 5.6$, and $86.86 \pm 14.63 \mathrm{MPa}$, respectively, shown in Fig. 5(h). The calculated ultimate strengths were $2.43 \pm 0.45,3.76 \pm 0.07,6.92 \pm 1.34,7.20$ $\pm 0.1 \mathrm{MPa}$, respectively, for the MFT constructs (Ref 86).

A straight microchannel was fabricated in order to investigate the bonding quality having dimensions of $50 \mu \mathrm{m}$ height, $200 \mu \mathrm{m}$ width, and $4 \mathrm{~cm}$ length, and it was tested accordingly. For the appearance and growth of Saffman-Taylor fingers, the device performance has been monitored until it becomes stable, known as "inflation stability" (Fig. 6a). To identify the channel behavior the results are presented in a $2 \mathrm{D}$ diagram at a given
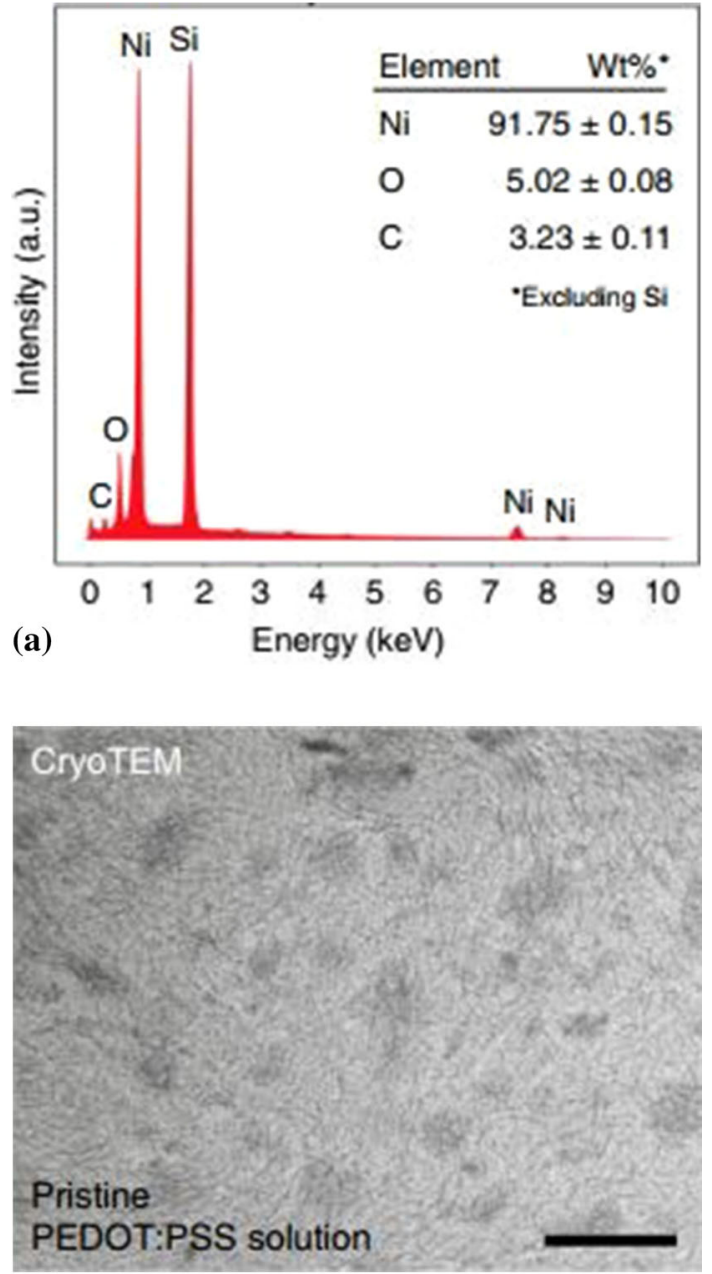

(b)

Fig. 4 (a) Energy-dispersive spectroscopy (EDS) of fabricated metal nanostructures (Ref 84), (b) CryoTEM image of a pristine PEDOT: PSS solution (Ref 85). Licensed under Creative Commons Attribution 4.0 International Public License, https://creativecommons. org/licenses/by/4.0/

pressure, as shown in Fig. 6(c). According to the results, the interface between the 3D-printed part and PMMA sheet became leakproof because of achieving holding strength of the doublecoated adhesive tape. Shear rate distribution was also evaluated across a line parallel to the channel width as Fig. 6(b). The safe zone for performing inertial microfluidic experiments is seen in the green area in Fig. 6(c). Experiments show that SaffmanTaylor fingers begin to appear when pressure is more than 82.6 psi. When it was run at high pressure in channels, any delamination or deformation was not observed (Ref 87).

\section{Potential Challenges in Future}

Future studies in 3D printing will likely involve the development of new printable metals for structural elements. Printing of large and bulk components can be focused. In order to enable strength, flexibility, and safety further research is required for the evaluation of the mixtures of materials and printing techniques. Comparatively less-expensive 3D printers 


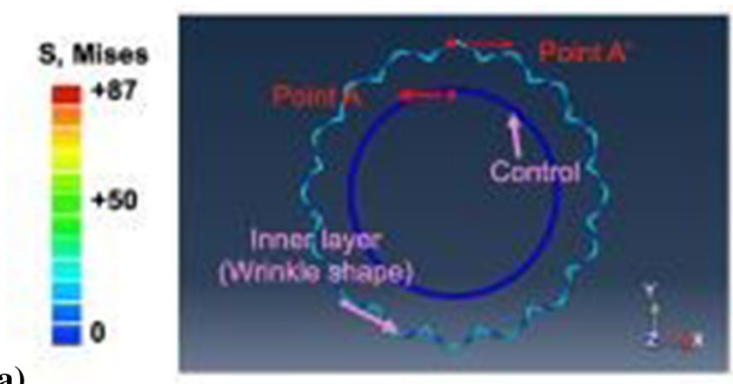

(a)
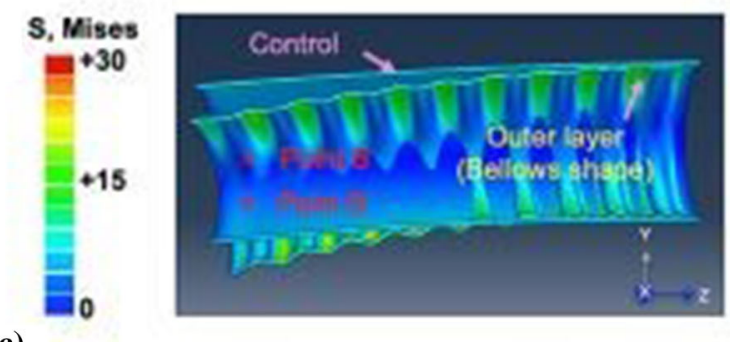

(c)

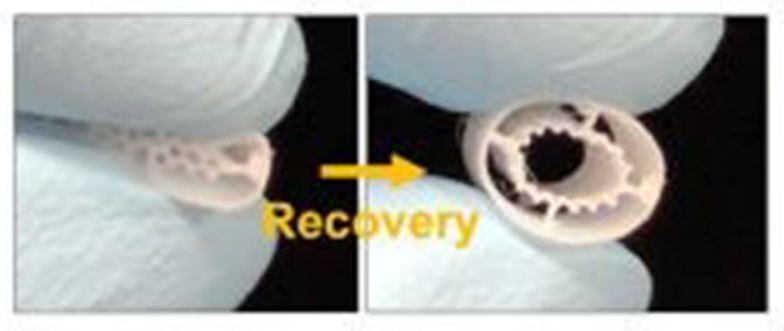

(e)
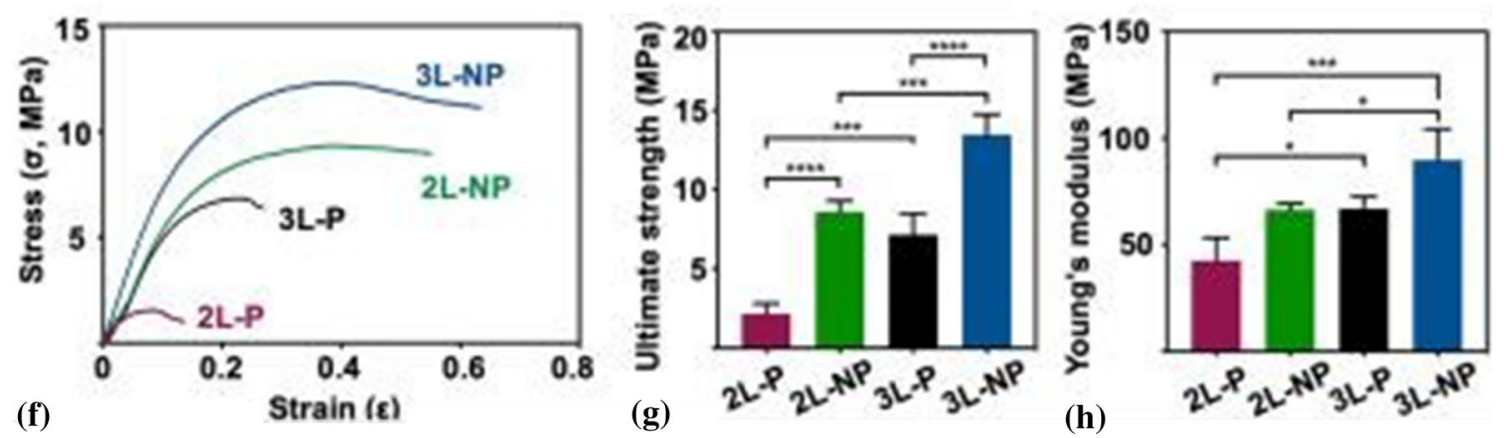

Fig. 5 Computational and experimental analysis of the mechanical characteristics of the winkle and the bellows' shapes. (a) Contour plot (0.2) MPa radial-directional pressure and deformed configuration, (b) pressure results comparison at each point A, A', (c) bending moment (40 N.mm) contour plot, (d) bending moment results comparison at each point B, B', (e) 3D-printed recovering test of 2-layer pore construct, (f) stress-strain responses of the scaffolds (2-, 3-layer pore/nonpore), (g) ultimate strength comparison, (h) Young's modulus comparison (Ref 86). Licensed under Creative Commons Attribution 4.0 International Public License, https://creativecommons.org/licenses/by/4.0/

have lower resolution and poorer surfaces that can lead to increased cost due to post-processing requirements. Besides printers with lower tolerance are not suitable for manufacturing products for assembly works. Energy consumption, space, and setting requirement result in more cost in industrial machining. As a result, large production becomes more expensive in 3D printing compared to traditional machining (Ref 88). For the support of new applications in medicine, new printable and biocompatible material may be involved in the research. Research may also associate with the cost reduction in printing.
The field of 3D printing is still far away for the mass production of products to meet the demand of average customers. It has passed a long way in the last 2 decades through sophisticated printers that are too expensive to attract the nonspecialist. The environmental standards are not set to the equipment technology properly (Ref 89 ).

3D printing has several environmental impacts associated with the printing process. It has greater energy demand compared to the traditional machining processes. Volatile organic compounds, solvents, nanoparticles may pollute the environment. Toxicity emission from materials might harm 


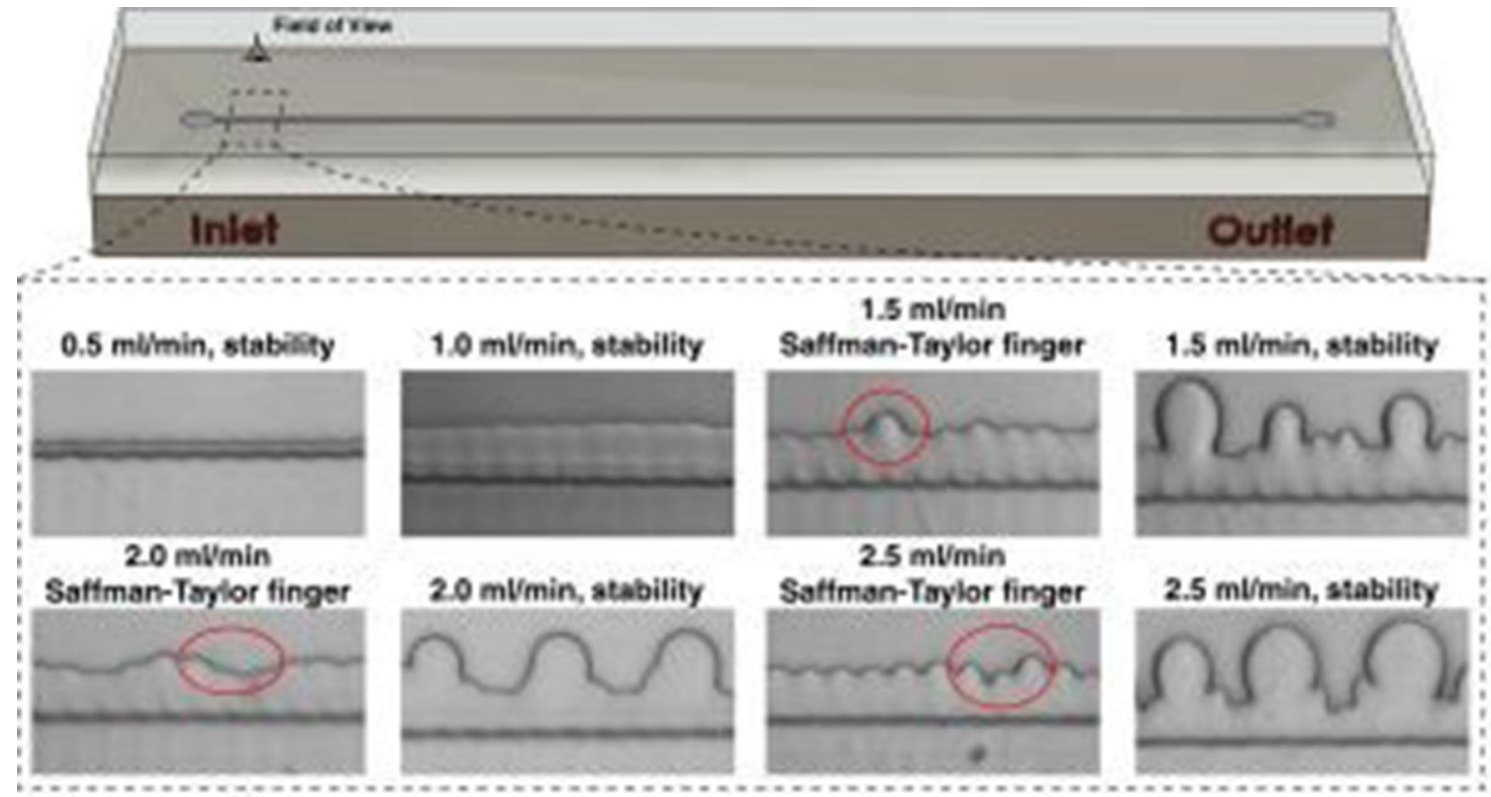

(a)
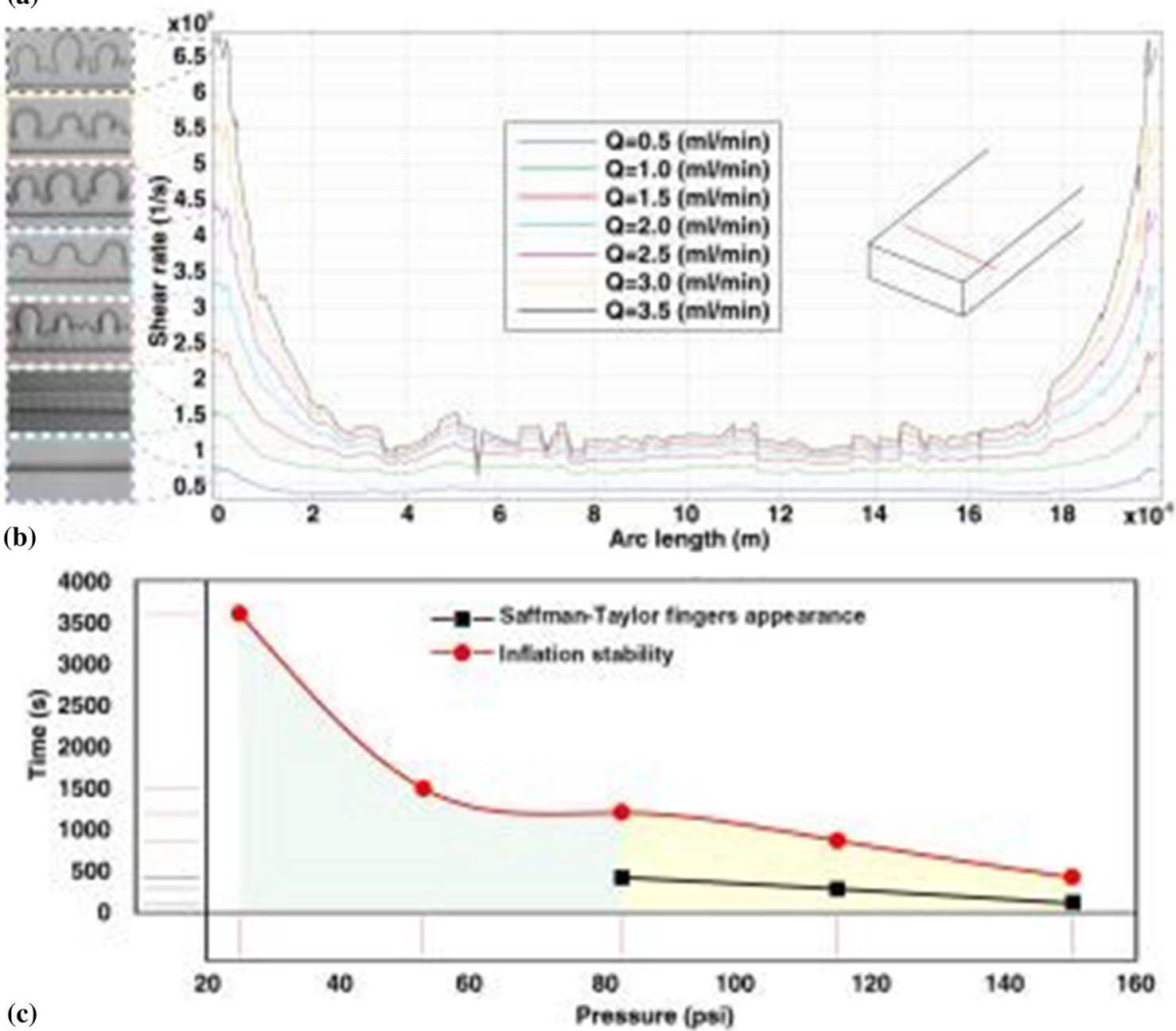

Fig. 6 (a) Analyzing the Saffman-Taylor finger criteria for the bonding quality in a microchannel versus various flow rates. (b) Shear rate distribution across a line parallel to the channel width. (c) The more the pressure, the faster the creation of Saffman-Taylor fingers (Ref 87). Licensed under Creative Commons Attribution 4.0 International Public License, https://creativecommons.org/licenses/by/4.0/ 
human health. Recycling of some materials is beyond processing. Some prospects are as well compared to other machining processes. It has greater raw materials efficiency and required less cutting fluid than milling. Green materials can be used as raw materials and thus protect the environment. Time consumption has decreased in prototype construction. Lower $\mathrm{CO}_{2}$ emission is observed during lightweight construction. Spare parts and tools have a greater lifetime and adaptability to climate change. Clinical sectors are highly benefited because of bioprinting (Ref 90).

\section{Conclusions}

$3 \mathrm{D}$ printing is a supportive advancement and probably the prime manufacturing technique in the future for different disciplines of engineering and medical science. It has shown dramatic development in recent years of using smart materials popularly known as 4D printing with conventional other materials. Incorporating nanomaterials to give strength and achieve desired mechanical properties is another milestone. Advancement in synthesizing biomaterials is another achievement probably beyond other conventional techniques. Though 3D printing has to pass a long way to be economical in industrial sectors, it has shown great advancement in a short period.

\section{References}

1. The third industrial revolution, The Economist, http://www.econo mist.com/node/21553017 (2012)

2. X. Yan and P. Gu, A Review of Rapid Prototyping Technologies and Systems, Comput. Des., 1996, 28, p 307-318

3. A.K. Sood, R.K. Ohdar and S.S. Mahapatra, Parametric Appraisal of Mechanical Property of Fused Deposition Modeling Processed Parts, Mater. Des., 2010, 31, p 287-295

4. W.E. Frazier, Metal Additive Manufacturing: A Review, J. Mater. Eng. Perform., 2014, 23, p 1917-1928

5. A. Simchi, F. Petzoldt and H. Pohl, On the Development of Direct Metal Laser Sintering for Rapid Tooling, J. Mater. Process. Technol., 2003, 141, p 319-328

6. L.E. Murr et al., Metal Fabrication by Additive Manufacturing Using Laser and Electron Beam Melting Technologies, J. Mater. Sci. Technol., 2012, 28, p 1-14

7. B.E. Carroll, T.A. Palmer and A.M. Beese, Anisotropic Tensile Behavior of Ti-6Al-4V Components Fabricated with Directed Energy Deposition Additive Manufacturing, Acta Mater., 2015, 87, p 309-320

8. S. Masood and W. Song, Development of New Metal/Polymer Materials for Rapid Tooling Using Fused Deposition Modeling, Mater. Des., 2004, 25, p 587-594

9. J. Jeon, H.C. Floresca and M.J. Kim, Fabrication of Complex ThreeDimensional Nanostructures using Focused Ion Beam and Nano Manipulation, J. Vac. Sci. Technol. B, 2010, 28, p 549-553

10. B.H. Cumpston et al., Two-Photon Polymerization Initiators for Three Dimensional Optical Data Storage and Micro Fabrication, Nature, 1999, 398, p 51-54

11. C. Vieu et al., Electron Beam Lithography: Resolution Limits and Applications, Appl. Surf. Sci., 2000, 164, p 111-117

12. Wohlers Report: Additive Manufacturing and 3D Printing State of the Industry (Wohlers Associates, 2015). ISBN 978-0-9913332-1-9

13. W. Lee et al., Multi-Layered Culture of Human Skin Fibroblasts and Keratinocytes Through Three-Dimensional Freeform Fabrication, Biomaterials, 2009, 30, p 1587-1595
14. F. Ning, W. Cong, J. Qiu, J. Wei and S. Wang, Additive Manufacturing of Carbon Fber Reinforced Thermoplastic Composites using Fused Deposition Modeling, Compos. B Eng., 2015, 80, p 369-378

15. Q. Zhang et al., 3D Printing of Graphene Aerogels, Small, 2016, 12, p 1702-1708

16. S.J. Leigh, R.J. Bradley, C.P. Purssell, D.R. Billson and D.A. Hutchins, A Simple, Low-Cost Conductive Composite Material for 3D Printing of Electronic Sensors, PLoS ONE, 2012, 7, p e49365

17. Z.X. Khoo et al., 3D Printing of Smart Materials: A Review on Recent Progresses in 4D Printing, Virt. Phys. Prototyp., 2015, 10, p 103-122

18. C. Liu, H. Qin and P. Mather, Review of Progress in Shape-Memory Polymers, J. Mater. Chem., 2007, 17, p 1543-1558

19. W. Huang, B. Yang, L. An, C. Li and Y. Chan, Water-Driven Programmable Polyurethane Shape Memory Polymer: Demonstration and Mechanism, Appl. Phys. Lett., 2005, 86, p 114105

20. H. Jiang, S. Kelch and A. Lendlein, Polymers Move in Response to Light, Adv. Mater, 2006, 18, p 1471-1475

21. S.V. Murphy and A. Atala, 3D Bioprinting of Tissues and Organs, Nat. Biotechnol., 2014, 32, p 773-785

22. T. Xu et al., Complex Heterogeneous Tissue Constructs Containing Multiple Cell Types Prepared by Inkjet Printing Technology, Biomaterials, 2013, 34, p 130-139

23. X. Wang, M. Jiang, Z.W. Zhou, J.H. Gou and D. Hui, 3D Printing of Polymer Matrix Composites: A Review and Prospective, Compos. Part B Eng., 2017, 110, p 442-458

24. N. Savage, VOXEL8 3D Printing Mixes Materials, Nature, 2017, 545, p S20-S20

25. D. Espalin, D.W. Muse, E. MacDonald and R.B. Wicker, 3D Printing Multifunctionality: Structures with Electronics, Int. J. Adv. Manuf. Technol., 2014, 72, p 963-978

26. K. Gnanasekaran et al., 3D Printing of CNT-and Graphene-Based Conductive Polymer Nanocomposites by Fused Deposition Modeling, Appl. Mater. Today, 2017, 9, p 21-28

27. P.E. Delannoy et al., Toward Fast and Cost-Effective Ink-Jet Printing of Solid Electrolyte for Lithium Microbatteries, J. Power Sources, 2015, 274, p 1085-1090

28. A.I. Shallan, P. Smejkal, M. Corban, R.M. Guijt and M.C. Breadmore, Cost-Effective Three-Dimensional Printing of Visibly Transparent Microchips Within Minutes, Anal. Chem., 2014, 86, p 3124-3130

29. N. Bhattacharjee, A. Urrios, S. Kang and A.T. Folch, Upcoming 3DPrinting Revolution in Microfluidics, Lab. Chip., 2016, 16, p 1720 1742

30. B. Cappi, E. Özkol, J. Ebert and R. Telle, Direct Inkjet Printing of Si3N4: Characterization of Ink, Green Bodies and Microstructure, $J$. Eur. Ceram. Soc., 2008, 28, p 2625-2628

31. M. Vaezi, H. Seitz and S. Yang, A Review on 3D Micro-Additive Manufacturing Technologies, Int. J. Adv. Manuf. Technol., 2012, 67, p $1721-1754$

32. U. Kalsoom, P.N. Nesterenko and B. Paull, Recent Developments in 3D Printable Composite Materials, RSC Adv, 2016, 6, p 60355-60371

33. X. Wei, D. Li, W. Jiang, Z. Gu, X. Wang, Z. Zang et al., 3D Printable Graphene Composite, Sci. Rep., 2015, 5(11181), p 1-7

34. S. Guo, K. Qiu, F. Meng, S.H. Park and M.C. Mcalpine, 3D Printed Stretchable Tactile Sensors, Adv. Mater., 2017, 29, p 1701218

35. J.T. Muth, D.M. Vogt, R.L. Truby, Y. Mengüç, D.B. Kolesky, R.J. Wood et al., Embedded 3D Printing of Strain Sensors Within Highly Stretchable Elastomers, Adv. Mater, 2014, 26, p 6307-6312

36. M.N. Nadagouda, V. Rastogi and M. Ginn, A Review on 3D Printing Techniques for Medical Applications, Curr. Opin. Chem. Eng., 2020, 28, p 152-157

37. A. Butscher, M. Bohner, N. Doebelin, S. Hofmann and R. Müller, New Depowering-Friendly Designs for Three-Dimensional Printing of Calcium Phosphate Bone Substitutes, Acta Biomater., 2013, 9(11), p 9149-9158

38. R.E. Saunders, J.E. Gough and B. Derby, Delivery of Human Fibroblast Cells by Piezoelectric Drop-on-Demand Inkjet Printing, Biomaterials, 2008, 29(2), p 193-203

39. T. Xu, W. Zhao, J.M. Zhu, M.Z. Albanna, J.J. Yoo and A. Atala, Complex Heterogeneous Tissue Constructs Containing Multiple Cell Types Prepared by Inkjet Printing Technology, Biomaterials, 2013, 34(1), p 130-139

40. B. Derby, Printing and Prototyping of Tissues and Scaffolds, Science, 2012, 338(6109), p 921-926 
41. W.C. Clem, S. Chowdhury, S.A. Catledge, J.J. Weimer, F.M. Shaikh, K.M. Hennessy et al., Mesenchymal Stem Cell Interaction with UltraSmooth Nanostructured Diamond for Wear-Resistant Orthopaedic Implants, Biomaterials, 2008, 29, p 3461-3468

42. M. Rashed, M. Ashraf, R. Mines and P.J. Hazell, Metallic Microlattice Materials: a Current State of the Art on Manufacturing, Mechanical Properties and Applications, Mater. Des., 2016, 95, p 518-533

43. A. Maurel, S. Grugeon, B. Fleutot, M. Courty, K. Prashantha, H. Tortajada, M. Armand, S. Panier and L. Dupont, Three-Dimensional Printing of a Lifepo4/Graphite Battery Cell Via Fused Deposition Modeling, Sci. Rep., 2019, 9, p 18031

44. H. Bikas, P. Stavropoulos and G. Chryssolouris, Additive Manufacturing Methods and Modelling Approaches: A Critical Review, Int. J. Adv. Manuf. Technol., 2016, 83, p 389-405

45. J.W. Stansbury and M.J. Idacavage, 3D Printing with Polymers: Challenges Among Expanding Options and Opportunities, Dent. Mater, 2016, 32, p 54-64

46. G. Dinga, R. Hea, K. Zhangb, N. Zhoub and H. Xu, Stereolithography 3D Printing of $\mathrm{SiC}$ Ceramic with Potential for Lightweight Optical Mirror, Ceram. Int., 2020, 46, p 18785-18790

47. A. Awad, F. Fina, A. Goyanes, S. Gaisford and A.W. Basi, 3D Printing: Principles and Pharmaceutical Applications of Selective Laser Sintering, Int. J. Pharm., 2020, 586, p 119594

48. F. Li, X. Ji, Z. Wu, C. Qi, J. Lai, Q. Xian and B. Sun, Digital Light Processing 3D Printing of Ceramic Shell for Precision Casting, Mater. Lett., 2020, 276, p 128037

49. Hu. Renzhi, X. Chen, G. Yang, S. Gong and S. Pang, Metal Transfer in Wire Feeding-Based Electron Beam 3D Printing: Modes, Dynamics, and Transition Criterion, Int. J. Heat Mass Transf., 2018, 126, p 877887

50. G. Ahn, K.H. Min, C. Kim, J.S. Lee, D. Kang, J.Y. Won and J.H. Shim, Precise Stacking of Decellularized Extracellular Matrix Based 3D CellLaden Constructs by a 3D Cell Printing System Equipped with Heating Modules, Sci. Rep., 2017, 7(1), p 1-11

51. H.K. Sezer and O. Eren, FDM 3D Printing of MWCNT Re-Inforced ABS Nano-Composite Parts with Enhanced Mechanical and Electrical Properties, J. Manuf. Process., 2019, 37, p 339-347

52. Z. Li, Li. Wang and G. Ma, Mechanical Improvement of Continuous Steel Microcable Reinforced Geopolymer Composites for 3D Printing Subjected to Different Loading Conditions, Compos. B, 2020, 187, p 107796

53. W. Liao, S. Zheng, S. Chen, L. Zhao, X. Huang, L. Huang and S. Kang, Surface Silanization and Grafting Reaction of Nano-Silver Loaded Zirconium Phosphate and Properties Strengthen in 3DPrintable Dental Base Composites, J. Mech. Behav. Biomed. Mater., 2020, 110, p 103864

54. N.S. Hmeidat, J.W. Kemp and B.G. Compton, High-Strength Epoxy Nanocomposites for 3D printing, Compos. Sci. Technol., 2018, 160, p 9-20

55. K.R. Ryan, M.P. Down and C.E. Banks, Future of Additive Manufacturing: Overview of 4D and 3D Printed Smart and Advanced Materials and their Applications, Chem. Eng. J., 2020, 8, p 126162

56. Y.C. Sun, Y. Wan, R. Nam, M. Chu and H.E. Naguib, 4D-Printed Hybrids with Localized Shape Memory Behaviour: Implementation in a Functionally Graded Structure, Sci. Rep., 2019, 9(1), p 1-13

57. H.W. Kang, S.J. Lee, I.K. Ko, C. Kengla, J.J. Yoo and A. Atala, A 3D Bioprinting System to Produce Human-Scale Tissue Constructs with Structural Integrity, Nat. Biotechnol., 2016, 34(3), p 312-319

58. Y.J. Tan, X. Tan, W.Y. Yeong and S.B. Tor, Hybrid MicroscaffoldBased 3D Bioprinting of Multi-Cellular Constructs with High Compressive Strength: A New Biofabrication Strategy, Sci. Rep., 2016, 6(1), p 1-13

59. L. Wang, Y. Ju, H. Xie, G. Ma, L. Mao and K. He, The Mechanical and Photoelastic Properties of 3D Printable Stress-Visualized Materials, Sci. Rep., 2017, 7(1), p 1-9

60. T. Billiet, M. Vandenhaute, J. Schelfout, S. Van Vlierberghe and P. Dubruel, A review of trends and limitations in hydrogel-rapid prototyping for tissue engineering, Biomaterials, 2012, 33, p 6020 6041

61. H.Y. Jeong, S.C. An, I.C. Seo, E. Lee, S. Ha, N. Kim and Y.C. Jun, 3D Printing of Twisting and Rotational Bistable Structures with Tuning Elements, Sci. Rep., 2019, 9(1), p 1-9

62. E. Monferrer, S. Martín-Vañó, A. Carretero, A. García-Lizarribar, R. Burgos-Panadero, S. Navarro and R. Noguera, A Three-Dimensional
Bioprinted Model to Evaluate the Effect of Stiffness on Neuroblastoma Cell Cluster Dynamics and Behavior, Sci. Rep., 2020, 10(1), p 1-12

63. C.D. Morley, S.T. Ellison, T. Bhattacharjee, C.S. O'Bryan, Y. Zhang, K.F. Smith and T.E. Angelini, Quantitative Characterization of 3D Bioprinted Structural Elements Under Cell Generated Forces, Nat. Commun., 2019, 10(1), p 1-9

64. M.M. Wang, R.L. Flores, L. Witek, A. Torroni, A. Ibrahim, Z. Wang and P.G. Coelho, Dipyridamole-Loaded 3D-Printed Bioceramic Scaffolds Stimulate Pediatric Bone Regeneration in Vivo Without Disruption of Craniofacial Growth Through Facial Maturity, Sci. Rep., 2019, 9(1), p 1-15

65. D.H. Ballard, K. Tappa, C.J. Boyer, U. Jammalamadaka, K. Hemmanur, J.A. Weisman and P.K. Woodard, Antibiotics in 3D-Printed Implants, Instruments and Materials: Benefits, Challenges and Future Directions, J. Print. Med., 2019, 3(2), p 83-93

66. Z. Wu, Su. Xin, Xu. Yuanyuan, B. Kong, W. Sun and S. Mi, Bioprinting Three-Dimensional Cell-Laden Tissue Constructs with Controllable Degradation, Sci. Rep., 2016, 6(1), p 1-10

67. K. Markstedt, A. Mantas, I. Tournier, H. Martnez Avila, D. Hagg and P. Gatenholm, 3D Bioprinting Human Chondrocytes with NanocelluloseAlginate Bioink for Cartilage Tissue Engineering Applications, Biomacromol, 2015, 16(5), p 1489-1496

68. C. Colosi, S.R. Shin, V. Manoharan, S. Massa, M. Costantini, A. Barbetta and A. Khademhosseini, Microfluidic Bioprinting of Heterogeneous 3D Tissue Constructs Using Low-Viscosity Bioink, Adv. Mater, 2016, 28(4), p 677-684

69. D.F. Duarte Campos, A. Blaeser, A. Korsten, S. Neuss, J. Jäkel, M. Vogt and H. Fischer, The Stiffness and Structure of Three-Dimensional Printed Hydrogels Direct the Differentiation of Mesenchymal Stromal Cells Toward Adipogenic and Osteogenic Lineages, Tissue Eng. Part A, 2015, 21(3-4), p 740-756

70. W. Zhang, I. Ullah, L. Shi, Y. Zhang, H. Ou, J. Zhou and W. Li, Fabrication and Characterization of Porous Polycaprolactone Scaffold Via Extrusion-Based Cryogenic 3D Printing for Tissue Engineering, Mater. Des., 2019, 180, p 107946

71. S. Ji, K. Dube, J.P. Chesterman, S.L. Fung, C.-Y. Liaw, J. Kohn and M. Guvendiren, Polyester-Based Ink Platform with Tunable Bioactivity for 3D Printing of Tissue Engineering Scaffolds, Biomater. Sci., 2019, 7(2), p 560-570

72. S. Hassanajili, A. Karami-Pour, A. Oryan and T. Talaei-Khozani, Preparation and Characterization of PLA/PCL/HA Composite Scaffolds Using Indirect 3D Printing for Bone Tissue Engineering, Mater. Sci. Eng. C, 2019, 104, p 109960

73. D. Gupta, A.K. Singh, A. Dravid and J. Bellare, Multiscale Porosity in Compressible Cryogenically 3D Printed Gels for Bone Tissue Engineering, ACS Appl. Mater. Interfaces, 2019, 11(22), p 20437-20452

74. A. Skardal, M. Devarasetty, H.W. Kang, I. Mead, C. Bishop, T. Shupe, S.J. Lee, J. Jackson, J. Yoo, S. Soker and A. Atala, A Hydrogel Bioink Toolkit for Mimicking Native Tissue Biochemical and Mechanical Properties in Bioprinted Tissue Constructs, Acta Biomater., 2015, 25, p 24-34

75. J.S. Park, T. Kim and W.S. Kim, Conductive Cellulose Composites with Low Percolation Threshold for 3D Printed Electronics, Sci. Rep., 2017, 7(1), p 1-10

76. E.J. Parry and C.E. Banks, COVID-19: Additive Manufacturing Response in the UK, J. Print. Med., 2020, 4(3), p 167-174

77. E.T.W. Tan, J.M. Ling and S.K. Dinesh, The Feasibility of Producing Patient-Specific Acrylic Cranioplasty Implants with a Low-Cost 3D Printer, J. Neurosurg., 2016, 124, p 1531-1537

78. K. Moiduddin, S. Darwish, A. Al-Ahmari, S. ElWatidy, A. Mohammad and W. Ameen, Structural and Mechanical Characterization of Custom Design Cranial Implant Created Using Additive Manufacturing, Electron. J. Biotechnol., 2017, 29, p 22-31

79. A. Haleem, M. Javaid and A. Saxena, Additive Manufacturing Applications in Cardiology: A Review, Heart J., 2018, 70, p 433-441

80. R. Van Lith, E. Baker, H. Ware, J. Yang, A.C. Farsheed, C. Sun and G. Ameer, 3D-Printing Strong High-Resolution Antioxidant Bioresorbable Vascular Stents, Adv. Mater. Technol., 2016, 1, p 1600138

81. M. Boffito, F.D. Meglio, P. Mozetic, S.M. Giannitelli, I. Carmagnola, C. Castaldo, D. Nurzynska, A.M. Sacco, R. Miraglia, S. Montagnani et al., Surface Functionalization of Polyurethane Scaffolds Mimicking the Myocardial Microenvironment to Support Cardiac Primitive Cells, PLoS ONE, 2018, 1397, p e0199896 
82. I. Molnar and L. Morovic, Design and Manufacture of Orthopedic corset Using 3D Digitization and Additive Manufacturing, IOP Conf. Ser. Mater. Sci. Eng., 2018, 448, p 012058

83. T. Toth, R. Hudak and J. Zivcak, Dimensional Verification and Quality Control of Implants Produced by Additive Manufacturing, Qual. Innov. Prosp., 2015, 19(1), p 9-21

84. A. Vyatskikh, S. Delalande, A. Kudo, X. Zhang, C.M. Portela and J.R. Greer, Additive Manufacturing of 3D Nano-Architected Metals, Nat. Commun., 2018, 9(1), p 1-8

85. H. Yuk, B. Lu, S. Lin, K. Qu, J. Xu, J. Luo and X. Zhao, 3D Printing of Conducting Polymers, Nat. Commun., 2020, 11(1), p 1-8

86. H. Nam, H.J. Jeong, Y. Jo, J.Y. Lee, D.H. Ha, J.H. Kim and J. Jang, Multi-Layered Free-Form 3D Cell-Printed Tubular Construct with Decellularized Inner and Outer Esophageal Tissue-Derived Bioinks, Sci. Rep., 2020, 10(1), p 1-14
87. S.R. Bazaz, O. Rouhi, M.A. Raoufi, F. Ejeian, M. Asadnia, D. Jin and M.E. Warkiani, 3D Printing of Inertial Microfluidic Devices, Sci. Rep., 2020, 10(1), p 1-14

88. L. Lee, A.M. Burnett, J.G. Panos, P. Paudel, D. Keys, H.M. Ansari and M. Yu, 3-D Printed Spectacles: Potential, Challenges and the Future, Clin. Exp. Optom., 2020, 103(5), p 590-596

89. M. Zastrow, 3D Printing Gets Bigger, Faster and Stronger, Nature, 2020, 578, p 20-23

90. B. Keppner, W. Kahlenborn, S. Richter, T. Jetzke, A. Lessmann and M. Bovenschulte, Focus on the Future: 3D Printing Trend Report for Assessing the Environmental Impacts, Umweltbundesamt, 2018, 8, p 35

Publisher's Note Springer Nature remains neutral with regard to jurisdictional claims in published maps and institutional affiliations. 